\title{
Economics, Darwinism, and the Case of Disciplinary Imports
}

\author{
By VALENTin Cojanu
}

\begin{abstract}
The problem of causality in economics is still contended by various epistemological alternatives. The article builds on the received view of Darwinism in economics and examines the way in which economics and biology find common ground in concepts and assumptions that reflect causal commonalities of the natural and the social world. We claim that the role the contingent pattern plays in understanding socioeconomic change provides reasons to concede corrections to a rule-based causal mechanism. The article concludes on the merits of advancing the ontological equivalent of interdisciplinary studies as one possible standard in reference to which to judge the epistemic adequacy of any import.
\end{abstract}

\section{Introduction}

The economists' query for causal explanation seems to have found in Darwin's theory of natural selection a much needed epistemic bridge between the natural and social orders of life; in short, a conceptual framework to analyze complex social systems. In contrast to equally vaunted alternatives like chaos theory or entropic models, Darwinian thought applies directly to habitats and their populating biota struggling for survival on the basis of encoded rules for inheritance and adaptation. In concurrence with them, it has gained credibility for its paradigmatic interpretation of nature, time, and history, often likened to a complete philosophical system founded on evolutionary logic.

Economists have frequently subjected their method of study to cross-fertilization from natural sciences, apparently because of their higher status among fellow sciences. Philosopher John Stuart Mill

I wish to thank four anonymous referees of the original article, whose comments contributed to the improvement of the article. The review process has been extremely helpful in orienting the article in a way that better addresses my viewpoint.

American Journal of Economics and Sociology, Vol. 72, No. 1 (January, 2013).

(C) 2013 American Journal of Economics and Sociology, Inc. 
(1874: 106) was one of its early advocates when he argued that missing explanations should be found in "some other science" so that an economist can get his policy recommendations accepted. Millian echoes may still be heard in appeals like that of Vromen (2001), who deplores the incapacity of mainstream economics to absorb new analytical tools as fast as other sciences expand their investigative possibilities. Darwin's theory of natural selection is a vivid example illustrating the influences currently feeding into economics across established disciplinary boundaries, from biology, neurology, game theory, computer science, and psychology, to name a few.

Other scholars beg to differ and condition interdisciplinary fertilization to the existence of a common ontological ground in the first place. The Kantian scrutiny of the rational mind had been premised on the observation, added in a later preface (1787), that "we do not enlarge but disfigure the sciences when we lose sight of their respective limits and allow them to run into one another" (Kant 1781: 11). Staying faithful to this credo has proved a laborious task for social science scholars. From Vico to Schumpeter, the idea of a universal social science has not eventuated in a complete system of thought, nor have the modern thinkers been more successful in unifying into a Grand Theory such novel yet disparate conceptualizations as "single natural-historical model of world" (Mayhew 1998), "realist social theorizing" (Lawson 2002), or "historical social systems" (Wallerstein 2004).

For Donald Schön (1979: 255), the impediments for a necessary reassessment of science according to the particular needs of social study "have more to do with problem setting than with problem solving, more to do with ways in which we frame the purposes to be achieved than with the selection of optimal means for achieving them." From this perspective, the parallel between economics and other sciences is valid (and so are the ensuing disciplinary imports) only to the extent it resonates within a common epistemology and not the other way round, or by substitution devising epistemic components (for example, ontologies and methodologies) consistent with conjectures hypothesized outside the social realm.

The import of Darwinian thought is particularly well suited to discuss the two alternative visions of science as it brings in an 
apparently negligible difference, yet a crucial one, as we shall suggest, between the biological individual and the social actor. This article's aim, therefore, is to expose the defective nature of disciplinary imports as long as they arise across themes of study of distinct ontological concern. Somewhat paradoxically, biology via evolutionary theory provides not only a case for questioning, but also one for strengthening the scope of interdisciplinary work, although from new perspectives. Our choice is to interpret Darwinism in reference to contingency, a concept defining a mode of reasoning of its own, and to explain the apparent difficulty of integrating it into social sciences and economics in particular.

At first sight, Darwinism may not seem the obvious conceptual platform against which we should aim to make our point. In lieu of exhibiting convergent intellectual lineage, the evolutionary theory remains so far a controversial issue of science depending on the competing paradigm one embraces. Were natural history to unfold anew from the beginning, it may necessarily arrive at the same outcomes (encoded in life structures) if one adopts Simon ConwayMorris's view of convergent evolution, as much as it may lead to different ones (arbitrarily determined) if one listens to Stephen Jay Gould's plea for punctuated equilibrium.

Yet, it is our claim that opposing the basic premises of the two systems of thought, in other words opposing optimal design (that is, the lawful process of selection and adaptation) to contingency (that is, the fragmentary and directionless evolutionary chain), possibly plays a bigger role in our theorizing about the social and economic world than mere interdisciplinary fertilization suggests. As scholars of diverse proclivities have noticed (for example, Dietz, Burns, and Buttel 1990; Thurtle 1998; Runciman 2005; Prindle 2006; Corning 2008; Abrantes and El-Hani 2009), biologists' indecisiveness has implications so profound that they trespass their subject matter and touch on the very foundations of science. We in effect witness a major paradigm shift heralding a post-Darwinian era of a new theory altogether. So, this article suggests, Darwinism's domestic controversies serve well to confront what its possible transition to "a meta-philosophy of life's change" (Prindle 2006) would possibly mean for economic and social thought. 
The argument proceeds gradually from an exposition of Darwinianbased ontology of economics to a rereading of evolutionary tenets in a code characteristic of the last developments. According to this plan, the second section examines the way in which economics and biology find common ground in concepts and assumptions that reflect causal commonalities of the natural and the social world. Not only has this interchange eventuated in a paradigmatic ontology for the use of economists, but it has also changed for good the basic economic tenets of rationality and causality.

As our article emphasizes, Darwinian logic was not only a product of careful and systematic collection of scientific evidence, it was also a reflection on the complexity of life, a professed understanding of sequences of unique events necessarily leading to superior forms of life. Evolutionary economic thought seems to have preserved Darwin's belief that determinacy is left no alternative except for divine intervention. A third section questions that opinion and claims that the role contingency plays in understanding chance and change, the two defining components of the historical patterns of evolution, provides reasons to concede corrections to a rule-based causal mechanism. The article concludes on the merits of advancing the ontological equivalent of interdisciplinary studies as one possible standard in reference to which to judge the epistemic adequacy of any import.

\section{Overview of a Darwinian Ontology of Economics}

The scholarship of evolutionary economics of the last two decades, of which Hodgson (2009) offers an exemplary collection, builds the case for understanding economic behaviour as ultimately a reflection of the principles of natural selection. Underpinned by varied analytical trials, including mathematical and game theory modeling, as well as laboratory and field experiments, the biological shaping of social action construes a new genre of rationality within a causal mechanism both more appealing to the needs of studying a wide array of patterns of human behaviour (for example, cooperation and competition, altruism and self-interest, reward and punishment), and more sensitive to changing social contexts than the neoclassical economics that it purports to replace. 
Although who qualifies as Darwinian may still be a puzzle (compare Prindle 2006; Bowler 2009), Darwinism itself is commonly understood (Dietz, Burns, and Buttel 1990; Nichols 2002; Fracchia and Lewontin 2005) in its neo-Darwinian synthesis, which typically explains evolution by random mutation, natural selection, genetic drift, and chance factors. In this expression, the essential feature of the mechanism of natural selection is its emergence at the behest of both necessity and chance: selective pressure leads to local adaptation of useful traits preserved on the basis of random variations of the genetic material. Evolutions so concur to orderly outcomes in which individuals compete for survivability benefits.

Many have recognized in Darwin's theory a conscious analogue to the $18^{\text {th }}$-century economics propounding Thomas Malthus's "struggle for existence" and Adam Smith's "laissez-faire" concepts (Gould 2007: 224; Comfort 2008; Hodgson 2009; Bowler 2009). Economists later returned the favor to biology when Marshall and Veblen infused economic analysis with evolutionary tenets. Although marred by hesitant departure from "mechanics" in the case of Marshall (Raffaelli 2008) and "psychologism" in the case of Veblen (Becker 2007), the inspiration they drew from Darwinism was influential in opening economics to adjacent fields of social science like sociological, historical, and institutional research.

It is of no concern here why such early calls were overpowered by the then ascending neoclassical current. What matters instead is that presently economics is remodeling its canonical model of monetary payoff-maximizing actors in a way that credits Marshall's assertion that "the Mecca of the economist lies in economic biology rather than economic dynamics" (1890: 19). Contemporary homo economicus is endowed with selective characteristics such as "maladaptive traits" (for example, altruism) for the survival values they confer on population (Simon 1990); "reasoning instincts" for their adaptive capability to express human intentionality (Cosmides and Tooby 1994); or "informational inputs" for enabling formal research to account for cultural diversity (Vromen 2001).

In-depth explorations of evolutionary economics take one step further from the use of analogy and metaphor and look for an economic theory proper based on "genotypes" and "phenotypes" 
operative in social environments such as technology, business, or science. The essential features of the selectionist paradigm have been translated into full-fledged economic models like Population-VarietyReproduction-Selection (PVRS) (Lawson 2003: ch. 5) or Generative Social Selection (GSS) (Hodgson and Knudsen 2008). These works converge in adopting the customary evolutionary "RIL formulation" ("replicators," "interactors," and "lineages") (compare Abrantes and El-Hani 2009), as do they also in pointing to social specificities that would make direct translation of Darwinism into economics unworkable.

On the one hand, analytical frameworks like PVRS or GSS work toward virtually complete ontological models based on the properties of some genetic makeup known as replicators (for example, habits and routines, social rules, but also knowledge, techniques) to store, transmit, and ensure copying fidelity of codified information among the social units of selection known as interactors (for example, social practices, firms, and institutions, but also ideas, values, and styles of thought). Competition takes place within a self-reproducible environment in which human dispositions and propensities, for example, will be important sources of variation.

On the other hand, these models and related literature (for example, Dietz, Burns, and Buttel 1990; Nelson 2006; Martins 2009) admit that selection in socioeconomic environments has nothing to do with biological survival and growth. Appropriating Darwinian thought as a universal way of theorizing, they say, should not distract us from seeing that the ontologies of the human social world and biological structures are different: the social realm features social preferences and values, acts of whim, human agency, and emergent experiences that fall short of developing a reproductive capability of their own and are unlikely to submit themselves to the evolutionary logic.

This qualification notwithstanding, common sense observations about, say, survivability of profitable firms or extinction of unprofitable ones, as well as evolutionary analysis applied to actual economic behavior (for example, Stoelhorst 2007) show undeterred fascination with Darwinism thanks to its "paradigmatic metanarrative" (Stuart-Fox 1999) providing the causal mechanism of variation and selective retention to social evolutions. 
As is the case of all disciplinary imports, whether Darwinism is being adopted as a methodological tool or as a system of thought seems to rest on a particularly thin argument: the social mechanism does exhibit working functionality within the logic of natural selection in relation to reproductive differential success. Biology thus provides an explanatory framework within which evolution of biotic or social systems is viewed as a lawful process of selection and adaptation with in-built directionality (towards survivability benefits). "The principle of determinacy or universal causation," argues Hodgson (2004: 178), is the necessary ontological position on which to found the selective mechanism. The causal process, he concludes, should focus "on its key processual algorithms. Even if every step in the process cannot be determined in detail, the exploration of the algorithmic process itself helps to provide an explanation. The key algorithmic process emphasized by Darwin was natural selection" (2004: 190).

Darwinian social theorizing has been disputed on various grounds. Some claim that non-biological Darwinism is "vacuous, culturally impoverishing, or downright dangerous" (Comfort 2008), while more critical interventions warn of the loss of much that is essential to the understanding of social/cultural change when the explanation favors the general reduction of history to evolutionary change (Thurtle 1998; Fracchia and Lewontin 2005).

We aim at lifting the veil on the "concealed" part of the social reality that cannot possibly find inclusive resolution on the evolutionary methodological path. This is not to deny altogether the validity of the evolutionary argument. A case in point is "ecological economics" formulating the basic tenets according to which the human species accommodates itself to the surrounding natural environment. As one author put it, "we are, in effect, joint participants in a biological contract" following our basic vocation as individuals and families in "a collective survival enterprise" (Corning 2008).

The contour of our ensuing argument may be previewed in table 1 opposing Darwinism to a number of "pluralistic correctives" (Gould 2007: 449) or "paradigm shifts" (Erwin 2007) that biologists themselves find suitable to amend Darwinian logic. ${ }^{1}$

Scholars of Darwinism in fact correct their study by regular recourse to new evolutionary findings (compare Nichols 2002; Hodgson 2004; 
Table 1

Principles of Natural Selection and Correctives

\section{Evolution by natural selection}

Evolution advances by chance

mutations of the genetic

material and by selective

incorporation of some of this

variation into altered

organisms.

\section{Inberitance}

Evolution preserves favored traits out of the orderly struggle of individual organisms for survivability benefits within local populations.

\section{Adaptation}

The result of natural selection is adaptation that results from accumulation of those favored genes within populations.

\begin{abstract}
Chance acts as agent of evolutionary change, while differential survival has little to do with the deterministic, adaptive struggles of organisms.
\end{abstract}

The process of selection takes place at several levels of a bierarchy of individuals, and in conjunction with events of branching speciation.

Based on Darwin ([1859] 1867) and Gould (2007: 223-228, 449).

Runciman 2005; Prindle 2006; Corning 2008). Selection at several hierarchical levels, for example, is now a common multi-level Darwinian approach, which proves that group selection or evolutionary game theory lead to evolving cooperative/successful strategies in managing the common goods. However, piecemeal amendments to Darwinism have accumulated to the point these correctives suggest a role for a logic of its own, a new logic of social and cultural systems fundamentally different from that of biological populations in the same way Darwin's theory of natural selection marked a decisive shift from creationism. 
In what follows, we look at the assumption that places history, one of "the most difficult of the sciences" McNeill (2001), as "explanatory paradigm" in a system of thought that combines "discrete systemic logic and contingent actions" (Fracchia and Lewontin 2005) to explain evolutionary patterns.

\section{A Reinterpretation of Evolutionary Patterns Based on the Role of Contingency}

Contending pairs of arguments in relation to the limits of the principles of natural selection reflect more than mere work in progress. According to Gould (2007: 248), the corrective framework has also been extended into non-biological fields ranging from human tools and technologies to learning theory, or to dynamics of human organizations. As this enumeration suggests, the correctives reinterpret the epistemological basis of integrating history into science: the empirical base these socioeconomic studies work with is set against historical patterns of human behavior, which may or may not include selectionist evolutionism.

In spite of its emphasis on cumulative change and transitional variations, Darwin's legacy has barely offered support in that direction. Only "miraculous interposition," wrote Darwin in 1861 ([1859] 1998: 370), may (implausibly) interfere with lawful evolutionary change; the missing evolutionary links that rule out divine intervention are explained by "the extreme imperfection of the geological record" ([1859] 1867: 265) or by "the poorness of our paleontological collections" ([1859] 1867: 270). In fact, the apparently flawless logic of his exposé On the Origin is interrupted by recurrent digressions on the evidence "on an enormous scale" ([1859] 1876: 264) of absent transitional links between species. Sudden appearance of whole groups of species "would be fatal to the theory of evolution through natural selection" ([1859] 1876: 282).

In light of newer evidence, Darwin's dichotomized view of "divinity vs. geological records" seems too limited. The discovery of the Cambrian fossils of the Burgess Shale in 1909 set out decades of scholarly debate inviting revisions of the scientific method in respect to explanations of a historical nature. An incredibly preserved geological 
formation, the Burgess Shale testifies for fragmented, not smooth, evolutionary chains, and for inferior, not better, designs that, as it happens, were marked for successful adaptation. The evidence, as presented, for example, in Gould (1989) we have now of the surviving lineages, an unremarkable minority of that geological moment, does not stand in dissonance with Darwinian principles but confirms that his hesitations were due.

Darwin's ironic stance against divine intervention is nevertheless apt to reflect a profound philosophical dilemma as much of his times as of ours though. Philosopher William James (1884: 22) shed light on one alternative (Darwin's) when presenting his view of the meaning of life:

The creator's plan of the universe would thus be left blank as to many of its actual details, but all possibilities would be marked down ... But the rest of the plan, including its final upshot, would be rigorously determined once for all. So the creator himself would not need to know all the details of actuality until they came.

Yet, his contemporary and no less meditative novelist Mark Twain ([1898] 2000: 27) was convinced that behind the human world's visible order lies comprehensible yet elusive causation. He penned Satan, a supernatural character, explaining to a mortal companion:

To skip any one of the billion acts in Columbus's chain would have wholly changed his life. I have examined his billion of possible careers, and in only one of them occurs the discovery of America. You people do not suspect that all of your acts are of one size and importance, but it is true; to snatch at an appointed fly is as big with fate for you as is any other appointed act.

We follow this dispute in the following and argue that a reinterpretation of Darwinian thought is due in light of the role the contingent pattern plays in understanding change, whether of evolutionary, economic, or cultural nature. Used interchangeably with randomness, uniqueness, or arbitrariness, contingency emerges from the "shaping of present results by long chains of unpredictable antecedent states, rather than immediate determination by timeless laws of nature" (Gould 2007: 211). Contingency is about the way we account for change and for chance in one seamless stream of thought. 
As mentioned, much of the debate is inspired by Darwin himself and a rereading of primary sources conflates the controversial nature of the originator's idea. In all six revised editions of the Origin, he restates his belief "that Natural Selection has been the main but not exclusive means of modifications" (Darwin [1859] 1867: 6). Is this just a marginal note, being the very last sentence of its prefatory text? Probably not, as mindful of possibly other accommodating explanations, Darwin inserts a conclusive remark that seemingly refutes the determinacy principle: "A grain in the balance may determine which individuals shall live and which shall die . . The slightest advantage in certain individuals, at any age or during any season, over those with which they come into competition, or better adaptation in however slight a degree to the surrounding physical conditions, will, in the long run, turn the balance" ([1859] 1867: 411, emphasis added).

If it is correct that one has therefore reasons to concede corrections to a rule-based causal mechanism, we should then de-emphasize (without denying) the role of the selectionist paradigm and attempt to turn those tiny particulars (read: historical accidents) that disrupt apparently transitional evolutionary states into a comprehensible account. For Fracchia and Lewontin (1999), the starting task should aim at correcting the flawed substitution of the metaphor "of evolution for history," a malign consequence, they argue, of "the grand twentieth-century movement to scientize all aspects of the study of society." In their analysis, the restrictiveness of the contingent pattern of differential reproduction varies from "very strong constraints on which states may succeed each other" in evolutionary contexts to "purely random differential survival" in historical frames. The replication process may thus actually unfold in such unpredictable patterns that causation becomes impossible to discern. If we proceed to the next level and attempt to integrate contingency in our explanatory framework, a double set of difficulties arises.

\section{Understanding Chance}

Our concept of causality needs further revising to account better for facts of historical nature. Even if this field of investigation is gaining ground as we speak, attempts have been made to acknowledge that 
unique events "always involve an element of arbitrariness, to analyse events at a level of abstraction at which their particularities matter and are not (often) repeated" (Runde and de Rond 2009). As noted, the underlying rationale of the corrected Darwinian logic is partly explained by mutations to DNA, although it should also accommodate fragmentary or indiscernible evolutionary chains whose occurrence lies in the realm of possible historical events, too.

The implication is twofold: things may happen because of prior, pre-determined, knowable circumstances (for example, genetic codes, commodity abundance, factor endowments) that support enduring structures of society (that is, market economies, gains from trade), but discontinuous or disruptive jumps in human evolution may equally plausibly be the norm. Increased efforts have been lately independently arrived at findings proving that dominating features of socioeconomic reality as represented by such events as technology and innovation (Bower and Christensen 1995), market entry (Runde and de Rond 2009), economic forecasting (Taleb 2009), or institutional setting (Wagner 2010) are able to set in motion unrelated causal chains with greater frequency than usually assumed.

It would now be futile to ask which sequence of events, of chance, or of necessity is prevalent in the social realm to establish so a possible standard against which to accept or not the received Darwinian thought; their very co-existence speaks for a radically new interpretation of life's narrative. The interplay between history and social theory admit a different, historically based evolutionary logic. A model of replication and interaction, adapted though to account for facts of social nature that escape evolutionary logic, cannot confer "accidents" as important an explanatory role as granted to "algorithmic" patterns of evolution.

A way out of this conundrum is suggested by a relatively new tendency to accommodate the contradictory and idiosyncratic facts of social reality in eclectic perspectives of socioeconomic evolutions. Lawson (2003) argues that any explicative mechanism (or "transformational model" in his parlance) should be derived in an a posteriori manner to be able to illuminate "the appearance of order, the matching of part and whole, of individual and environment, even when this outcome is not the product of conscious design" (2003: 125). In similar 
vein, other conceptual developments like "synergistic selection" (Corning 2008), "multi-temporal social systems" (Liagouras 2009), or "path dependent processes" (Martin 2010) have been added toward a unifying epistemological vision.

Coalescing disparate explanations around historical patterns reveals common, not different, ontologies across disciplines in the same way mathematical logic connects scientists towards an algorithmic interpretation of nature. In the words of Gould (1999: 298), "contingency represents the historian's mode of knowability." Inheritance and variation work by sorting out individuals partly within selective mechanisms reducible to known characteristics of organisms (for example, the base pairs of DNA) and testable relative to expected outcomes (for example, differential reproductive success). At the same time, the contingent detail concurs with non-negligible force in turning unpredictable into undetermined evolutionary threads by particulars of organic and inorganic origin (for example, mass extinctions, natural calamity, or non-adaptive side consequences).

Any interdisciplinary parallel may be traced (on the same ontological ground) as long as the natural order exhibits trends of both evolutionary and historical nature. In the social domain, usually several contingencies are at play: tipping moments of social unrest, plagues, emerging "power jumps," irrecoverable scientific losses, extreme dissolution of mores, and so forth. In like approaches, it is admitted that socioeconomic domains are amenable to study even though "the ultimate truth on the matter may be forever beyond our grasp" (Runde and de Rond 2009: 17). Bundles of simultaneous interplay of sequences of events undergo variations that render differences of the same sequence's/event's manifestations irreconcilable in time in the same way natural selection departs from controllably encoded processes.

\section{Understanding Change}

A second difficulty of integrating contingency arises as we attempt to find an evolutionary role for accidents, that is, evolutionary phases diverging from the visible threads linked to adaptation to changing local environments on the basis of our presumptive knowledge about 
what "adaptation" means in the first place. The received Darwinian ontology remains undecided as to whether to expurgate residual developmental errors from the selective process. On the one hand, Hodgson and Knudsen (2008) argue about the supposed capability of selection to retain "relatively successful adaptations" and generate "increasing complexity"; on the other hand, Dietz, Burns, and Buttel (1990) adopt the view that "the rules favored by cultural evolution will not necessarily be the rules that maximize genetic fitness" (1990: 160).

This hesitation, however, does not actually call for a resolute defense of either viewpoint. Once accidents enter the picture, the need to pit superior (read: complex) against inferior (read: suboptimal) outcomes (that is, systems or institutional contexts) within a universalized theorizing schema disappears. Adaptation among social units of selection maintains its instrumental position in providing progress with evolutionary meaning, in other words we can assert whose selective characteristics prove successful on the basis of value judgments ascribed to the evidence we collect. However, on a historical scale, and that does not mean doing the historian's work, our perception of the mechanism of institutional change is only marginally affected by such determined processes. Indeterminacy plays its role, visibly enough to play down any perspective of rule-based explanatory mechanisms and hence inherent directionality.

Apparently, it cannot be simpler than that: the modern (for example, the information age) prevails over the rudimentary (for example, the machine age) in any account of economic progress, while fitness peaks and troughs inside each era may be reasonably acknowledged. It would be quite possible though, that our endpoints on the historical passage be happenstances of parallel, maybe intersecting, yet not necessarily continuous progressions.

Diamond's (2005) account of societal survivability provides one of the closest representations of evolutionary accidents he subsumes under the term "environment": a five-set framework of contributing factors like environmental damage, climate change, peaceful vicinities, thriving neighbors, and societal responses to environmental problems. His storytelling, supported by first-hand evidence, goes through rises and falls of ancient and modern civilizations at the impact of collapse, "a drastic decrease in human population size and/or political/ 
economic/social complexity, over a considerable area, for an extended time" (Diamond 2005: 3).

According to the argument he adduces, there remains little doubt that a sizeable part of human evolution (for example, the Maya society in Central America, the Anasazi society in the U.S. Southwest, or the Norse Greenland) was doomed to extinction in spite of behavioral complexity and facing similarly harsh environments as their contemporary survivors. Instead of developmental stages, he found chains of historical events encompassing uniquely models of interaction between people, environment, and cultures.

Gould's reflections on the Burgess fauna invite to honest evaluation of the causal framework for historical disciplines because "we must admit that we have no evidence whatsoever-not a shred-that losers in the great decimation were systematically inferior in adaptive design to those that survived. Anyone can invent a plausible story after the fact" (Gould 1989: 236). Memories of the near past suffice to reveal the ambivalence surrounding a position that favors increasingly "superior" behavioral patterns (whatever it would mean). Selection of a sort took place both in communism and capitalism and surviving social practices and rules have been perpetuated within each economic system according to their own value judgments. And as was observed (for example, Eyal, Szelényi, and Townsley 2001), communism may have succumbed to the destructive effect of resource misallocation, although its vices and virtues live on in novel institutional recombination.

Conceptualizing the causal efficacy of social structures errs on the side of circular reasoning: better, functional institutions persist because persistence within a circumstantial context is what makes them better in the first place, not because of any prior confirmed hypothesis about their superiority. A moment's reflection prompts us to ask if transition (that is, selection of surviving institutions) is really the issue as to the sequential path of developmental stages of humankind, in the way scholars like Karl Marx and Thorstein Veblen bequeathed political and social thought. In spite or because of their markedly different justifications (compare Liagouras 2009), a stage evolution is what we continue to construe in the mainstream by assigning value judgments to ever subtler evolutionary forms, as exemplified by the widely adopted representation of hierarchies of varieties of capitalism. 


\section{Concluding Remarks}

Economics connects itself to biology on the premise that analogous causal mechanisms, but different ontologies provide the adequate explanatory framework in respect to which social and biological populations are parts of the same genre, that is, evolutionary thinking. This view is nevertheless built on an orderly course of events that is both cognoscible and adaptively superior, an assumption Darwin has never completely acknowledged. His own interpretation of the passage of time seems to have suggested alternative mechanisms of knowledge, in which chance and value judgments would cease to necessarily underpin survivability and superior purposes.

There is no doubt that the selection process is indeed at work in the interplay between chance and necessity to account for survivability benefits, only that the sequence of events at a historical scale also integrates the contingent pattern along the causal chain. The historical setting of the social actor is a culturally laden meaningful context, which is neutral and hence irrelevant to the biological individual. Likewise, some biologists seem inclined to allow alternative paths of evolutionary states to explain the innumerable combinations of biota, in actual or imaginary developments. Contingency, we imply, would adequately bring the ontology of evolutionary studies, of which economics is markedly a subaltern, to a common denominator.

The historical nature of evolutions requires converging interpretations of the concepts of chance and change within ontologies of equivalent significance. Irrespective of how much scientific evidence (for example, new fossil records or artifacts of primeval man's societies) we are able to amass, our theorizing of historical social systems should also make room for explanations emphasizing (1) uniqueness of contingent details, and (2) lack of inherent directionality of the observed sequences of events.

Economics as historical reconstruction of nature's social order subjects the evidence to tests found on our converging path to understanding its sense, its role, importance, and impact for human economic progress. The sensible distinction between the social actor and the biological individual rests on cultural attributions and historical significance. We may accept testing a wing's optimal size for 
aerodynamic or thermal effect but contend that such a technical exercise may be carried out with as much success for, say, an area's optimal growth size. However, the principle of "functional shift" applies in both instances in the sense that what might have been counted as non-adaptive features at one time remains so or becomes "functional" precisely because of our view of the historical whole at some other time.

Historical change is an ontological component that by definition plays a significant role in historical disciplines. Although the lapse of time may or may not uncover missing explanatory links, the interdisciplinary equivalence on this ground means that Darwinian thought be reduced to the role causal explanation plays in providing a realistic view of the social world. The idea that great or unexpected designs arise from trifling causes, or do not arise at all, is a historical premise not amenable to conventional experiments of testing and prediction, although it should nevertheless be part of our explicative framework. Exclusive reliance on the causal mechanism may just prove too elusive to pin down in a meaningful manner why things occur the way they do.

\section{Note}

1. Gould (2007) also refers to systems of thought that question the restrictiveness of Darwinian thought from perspectives different of his own (for example, "punctuated equilibrium") such as the neutral theory of molecular evolution introduced by Motoo Kimura in the late 1960s and early 1970s.

\section{References}

Abrantes, P., and C. Niño El-Hani. (2009). "Gould, Hull, and the Individuation of Scientific Theories." Foundation of Science 14: 295-313.

Becker, M. C. (2007). "Routines: A Brief History of the Concept." In Economics and the Social Sciences. Eds. Stavros Ioannides and Klaus Nielsen, pp. 233-261. Cheltenham, UK: Edward Elgar.

Bower, J. L., and Clayton M. Christensen. (1995). "Disruptive Technologies: Catching the Wave." Harvard Business Review 73(1): 43-53.

Bowler, P. J. (2009). "The Eclipse of Pseudo-Darwinism? Reflections on Some Recent Developments in Darwin Studies." Hist. Sci. xlvii: 431-443.

Comfort, N. (2008). "Cultural Darwinism." European Legacy 13(5): 623-637. 
Corning, P. A. (2008). "Holistic Darwinism. The New Evolutionary Paradigm and Some Implications for Political Science." Politics and the Life Sciences 27(1): 22-54.

Cosmides, L., and J. Tooby. (1994). "Better than Rational: Evolutionary Psychology and the Invisible Hand." American Economic Review, Papers and Proceedings 84(2): 143-148.

Darwin, C. ([1859] 1876). On the Origin of Species by Means of Natural Selection, $6^{\text {th }}$ Edition. London: John Murray.

—. ([1859] 1998). On the Origin of Species by Means of Natural Selection. Wordsworth Classics.

Diamond, J. (2005). Collapse, How Societies Choose to Fail or Succeed. Penguin Books.

Dietz, T., T. R. Burns, and F. H. Buttel. (1990). "Evolutionary Theory in Sociology: An Examination of Current Thinking." Sociological Forum 5 (2): $155-171$.

Erwin, D. H. (2007). "Darwin Still Rules, But Some Biologists Dream of a Paradigm Shift." New York Times June 26. http://www.nytimes.com/2007/ 06/26/science/26essay.html?_r=1\&pagewanted=print (accessed March 4, 2010).

Eyal, G., I. Szelényi, and E. Townsley. (2001). Making Capitalism Without Capitalists: The New Ruling Elites in Eastern Europe. London, New York: Verso Books.

Fracchia, J., and R. Lewontin. (1999). "Does Culture Evolve?" History and Theory 38(4): 52-78.

—. (2005). "Forum: Does Culture Evolve? 2. The Price of Metaphor." History and Theory 44: 14-29.

Gould, S. J. (1989). Wonderful Life. The Burgess Shale and the Nature of History. New York: W.W. Norton and Co.

- (1999). Leonardo's Mountain of Clams and the Diet of Worms: Essays on Natural History. New York: Three Rivers Press.

- (2007). The Richness of Life. Eds. Paul McGarr and Steven Rose. Vintage. Hodgson, G. M. (2004). "Darwinism, Causality and the Social Sciences." Journal of Economic Methodology 11(2): 175-194.

- . (2009). "Introduction." In Darwinism and Economics. Ed. G. M. Hodgson, pp. xi-xxxvi. Cheltenham, UK: Edward Elgar Publishing.

Hodgson, G. M., and T. Knudsen. (2008). "Information, Complexity, and Generative Replication." Biology and Philosophy 23: 47-65.

James, W. (1884). The Dilemma of Determinism. http://www.rci.rutgers. edu/ stich/104_Master_File/104_Readings/James/James_DILEMMA_OF_ DETERMINISM.pdf (accessed February 23, 2007).

Kant, I. ([1781] 2004). The Critique of Pure Reason. Trans. J. M. D. Meiklejohn. http://www.gutenberg.org/cache/epub/4280/pg4280.html (accessed May 12, 2011). 
Lawson, T. (2002). "Should Economics Be an Evolutionary Science? Veblen's Concern and Philosophical Legacy." Journal of Economic Issues XXXVI(2): 279-292.

- (2003). Reorienting Economics. London and New York: Routledge.

Liagouras, G. (2009). "Socio-Economic Evolution and Darwinism in Thorstein Veblen: A Critical Appraisal." Cambridge Journal of Economics 33: 1047-1064.

Marshall, A. ([1890] 1920). Principles of Economics, $8^{\text {th }}$ Edition. London: Macmillan and Co.

Martin, R. (2010). "Rethinking Regional Path Dependence: Beyond Lock-in to Evolution." Economic Geography 86(1): 1-27.

Martins, N. (2009). "A Transformational Conception of Evolutionary Processes." Evol. Inst. Econ. Rev. 6(1): 71-102.

Mayhew, A. (1998). "On the Difficulty of Evolutionary Analysis." Cambridge Journal of Economics 22: 449-461.

McNeill, W. H. (2001). "Passing Strange: The Convergence of Evolutionary Science with Scientific History." History and Theory 40: 1-15.

Mill, J. S. ([1874] 2000). Essays on Some Unsettled Questions of Political Economy, $2^{\text {nd }}$ Edition. Kitchener: Batoche Books.

Nelson, R. (2006). "Evolutionary Social Science and Universal Darwinism." Journal of Evolutionary Economics 16: 477-489.

Nichols, T. L. (2002). "Evolution: Journey or Random Walk?" Zygon 37(1): $193-210$.

Prindle, D. (2006). "Stephen Jay Gould as a Political Theorist." Politics and the Life Sciences 25(1-2): 2-14.

Raffaelli, T. (2008). "The General Pattern of Marshallian Evolution." In Marshall and Schumpeter on Evolution: Economic Sociology of Capitalist Development. Eds. Shionoya, Yuichi and Nishizawa, Tamotsu, pp. 36-47. Cheltenham, UK: Edward Elgar.

Runciman, W. G. (2005). "Forum: Does Culture Evolve? 3. Rejoinder to Fracchia and Lewontin." History and Theory 44: 30-41.

Runde, J., and M. de Rond. (2009). "Evaluating Causal Explanations of Samples of One." Unpublished paper. Cambridge, UK: Cambridge Realist Workshop Seminars.

Schön, D. (1979). "Generative Metaphor: A Perspective on Problem-Setting in Social Policy." In Metaphor and Thought. Ed. A. Ortony, pp. 254-283. Cambridge, UK: Cambridge University Press.

Simon, H. A. (1990). "A Mechanism for Social Selection and Successful Altruism." Science 250: 1665-1668.

Stoelhorst, J. W. (2007). "The Naturalist View of Universal Darwinism." In The Evolution of Economic Institutions. Ed. G. M. Hodgson, pp. 233-251. Cheltenham: Edward Elgar. 
Stuart-Fox, M. (1999). "Evolutionary Theory of History." History and Theory 38(4): 33-51.

Taleb, N. N. (2009). "Error, Robustness, and the Fourth Quadrant." International Journal of Forecasting 25: 744-759.

Thurtle, P. S. (1998). "The 'G Files': Linking 'the Selfish Gene' and 'the Thinking Reed'. http://prelectur.stanford.edu/lecturers/gould/commentary/thurtle. html (accessed May 12, 2011).

Twain, M. ([1898] 2000). The Mysterious Stranger. A Romance by Mark Twain. Electronic Text Center, University of Virginia Library. http://etext.lib. virginia.edu/toc/modeng/public/TwaMyst.html (accessed March 10, 2010).

Vromen, J. J. (2001). "The Human Agent in Evolutionary Economics." In Darwinism and Evolutionary Economics. Eds. John Laurent and John Nightingale, pp. 184-208. Cheltenham: Edward Elgar.

Wagner, R. E. (2010). Mind, Society, and Human Action - Time and Knowledge in a Theory of Social Economy. London and New York: Routledge.

Wallerstein, I. (2004). The Uncertainties of Knowledge. Philadelphia: Temple University Press. 